\title{
One- to 10-year Status Epilepticus Mortality (SEM) score after 30 days of hospital discharge: development and validation using competing risks analysis
}

Prapassara Sirikarn ${ }^{1,2}$, Porjai Pattanittum ${ }^{1}$ and Somsak Tiamkao $2,3^{*}$

\begin{abstract}
Background: Status epilepticus (SE) is an emergency neurological disorder that affects quality of life and is associated with high mortality risk. Three scores have been developed to predict the risk of in-hospital death, but these scores are poor discrimination of mortality after discharge. This study aimed to develop and validate a simple risk score for long-term mortality in SE patients.

Methods: This retrospective cohort study was conducted using SE patient data collected from Thailand's Universal Coverage Scheme database between the fiscal years of 2005 and 2015 and followed-up to 2016. Patients who died in hospital or within 30 days after discharge were excluded. Data were divided at random into either a derivation or validation set. A proportional hazards model for the sub-distribution of competing risks was fitted with backward stepwise method. The coefficients from the model were used to develop a point-based scoring system. The discrimination ability of the model was evaluated using a time-dependent receiver operating characteristic (ROC) curve.
\end{abstract}

Results: A total of 20,792 SE patients (with ages ranging from the first day of life to 99 years at first admission) were randomly separated into two groups: 13,910 in the development group and 6882 in the validation group. A subdistribution hazard model was used to determine nine predictors to be included in the final model, which was, in turn, used to develop the scoring system: age (0-19 points), male (two points), brain tumor (12 points), stroke (three points), cancer (11 points), diabetes (three points), chronic kidney disease (five points), pneumonia (five points), and urinary tract infection (four points). The possible total score ranged from zero to 64 and the cumulative incidence function was used to determine the probability of mortality associated with each total score within the first 10 years after the first admission. The area under the ROC curve (AUC) of the first to last time point ranged from 0.760 to 0.738 .

Conclusion: A nine-factor risk score for predicting 10-year mortality in SE patients was developed. Further studies should focus on external validity and including a range seizure types and duration of seizure as the predictors.

Keywords: Status epilepticus, Score, Predictive model, Long-term, Mortality

\footnotetext{
* Correspondence: somtia@kku.ac.th

${ }^{2}$ Integrated Epilepsy Research Group, Khon Kaen University, Khon Kaen, Thailand

${ }^{3}$ Division of Neurology, Department of Medicine, Faculty of Medicine, Khon Kaen University, Khon Kaen, Thailand

Full list of author information is available at the end of the article
}

(c) The Author(s). 2019 Open Access This article is distributed under the terms of the Creative Commons Attribution 4.0 International License (http://creativecommons.org/licenses/by/4.0/), which permits unrestricted use, distribution, and reproduction in any medium, provided you give appropriate credit to the original author(s) and the source, provide a link to the Creative Commons license, and indicate if changes were made. The Creative Commons Public Domain Dedication waiver (http://creativecommons.org/publicdomain/zero/1.0/) applies to the data made available in this article, unless otherwise stated. 


\section{Background}

Status epilepticus (SE) is an emergency neurological disorder that affects patients' quality of life and is associated with high mortality risk. A recent meta-analysis found that the pooled crude annual incidence rate of SE was 12.6 per 100,000 person-years (95\% confidence interval [CI]: 10.0 to 15.3$)$ and the case fatality rate was 14.9\% (95\% CI: 11.7 to $18.7 \%$ ) [1].

There are several factors that contribute to the risk of death in SE patients, but the key factors are age, duration of SE, and etiology [2, 3]. Moreover, previous studies found that comorbidities and complications were also major factors associated with mortality, for example, brain tumors, central nervous system (CNS) infection, septicemia, pneumonia, and shock [4-7]. Because death is a crucial outcome in SE, identifying the risk of death in patients with this condition can allow physicians to optimally manage their patients' care on an individual basis. Risk scores have been developed to assess the risk of death in SE based on several important factors in order to assist health care professionals in the therapeutic decision-making process.

Currently, there are three available scores to predict a patient's risk of in-hospital death. The most commonly used score is the Status Epilepticus Severity Score (STESS). This score was developed based on four predictors: consciousness, seizure type, age, and history of previous seizure [8]. Another is the Epidemiology-Based Mortality Score in Status Epilepticus (EMSE), which takes epidemiological data, including etiology, age, electroencephalogram (EEG), and comorbidity, into account [9]. Finally, the modified Status Epilepticus Severity Score (mSTESS) was developed from the STESS to more accurately predict mortality at discharge by including the patient's Modified Rankin Scale (mRS) in with the other predictors used in the STESS [10].

The STESS has also been applied to predict long-term mortality in SE patients, but was found to be a poor discrimination of mortality after discharge (the area under the receiver operating characteristic curve [AUC] was 0.676 (95\%CI: 0.516 to 0.833$)$ ) [11].

Most of the published studies mentioned above only followed SE patients through their hospital stay and lacked data predicting long-term mortality. The outcome of interest in this study is time-to-death after 30 days of hospital discharge. It was defined as time from the patient's first admission with a primary diagnosis of SE to death which including both direct (e.g. seizure, epilepsy, $\mathrm{SE}$ ) and indirect (e.g. SE complications, suicide, accidents, or underlying diseases [12]) causes of deaths by taking into account for the competing risks (e.g. senility, cardiovascular collapse). Thus, this study aimed to develop and validate a score to predict long-term mortality in SE patients that accounts for the presence of competing risks in order to avoid overestimating the of probability of death in SE, which tends to be a flaw in the conventional statistical methods that are used for this purpose $[13,14]$.

\section{Methods \\ Design and setting}

This was a retrospective cohort study. Data for this study was retrieved from the Thai Universal Coverage Scheme electronic database that recorded the information of over $75 \%$ of Thai citizens who admitted to hospitals within Universal Coverage Scheme. Data between the fiscal years of 2005 and 2015 (October 1, 2004 to September 30, 2015) were used and followed up for 1 year (until September 30, 2016).

\section{Patients}

Patients were eligible for inclusion in this study if their data were in the Thai Universal Coverage Scheme database and they were admitted to hospitals with a primarily diagnosis of SE based on the guidelines described in the International Statistical Classification of Diseases and Related Health Problems - 10th Revision (ICD-10) code G41 (Status epilepticus). The SE diagnosis was followed by the guideline of the International League Against Epilepsy in each version over past 10 years. There were no restrictions based on age, sex, or SE type. Eligibility was limited to those patients who had not died in hospital (discharge status of death) or within 30 days after discharge. Patients with incomplete data regarding their date of birth, date of admission, date of death, or cause of death were also excluded. All patient' data were anonymized and de-identified prior to extraction and analysis.

\section{Study variables}

The outcome in this study was time from the patient's first admission with a primary diagnosis of SE to death (including both direct and indirect causes). Deaths from the following causes according to the patients' death certificates were considered to be event of interest: (a) seizure, epilepsy, SE, (b) accident, suicide, (c) SE complications (e.g. pneumonia, septicemia), and (d) comorbidities (e.g. cancer, diabetes mellitus; Additional file 1: Figure S1). Competing risks events were senility, cardiovascular collapse, etc. (Additional file 1: Table S1 provides the details regarding event of interest and competing events in this study). Patients who were still alive at the end of the study (September 30, 2016) were censored data.

Predictors in this study included baseline demographic characteristics (sex and age at first admission), comorbidities, and complications (occurred during the followup period). ICD-10 codes were utilized to identify 
comorbidities and complications (Additional file 1: Table S2).

\section{Statistics}

The eligible study subjects were randomly split into a derivation set and a validation set at a 2:1 ratio. Characteristics of patients in both sets were reported as frequency and percentage for categorical data and median with minimum and maximum value for continuous data. A sub-distribution hazard function was used to develop a predictive model with competing risks $[15,16]$. Sensitivity analysis was performed based on selection algorithms, and the modified Bayesian information criterion for competing risks was used to select predictors for the final model [17]. The coefficients in the final subdistribution hazard model were used as a scoring system that followed by the method of Austin [14]. Although the concordance index (c-index) has been widely used to evaluate the performance of predictive models with time-to-event outcomes, the c-index tends to be misleadingly high when used to predict t-year risk. Thus, we deemed the time-dependent receiver operating characteristic (ROC) curve to be more appropriate to assess differences at each year point $[18,19]$. Statistical analyses were performed using the $\mathrm{R}$ statistical programming language [20] with the "crrstep" package [21] to select predictors, the "cmprsk" package [22] for fitting the subdistribution hazard model, and "riskRegression" package [23] for assessing the time-dependent ROC.

\section{Results}

Among the 24,818 SE patients who were admitted to hospitals included in the Thai Universal Coverage Scheme database between the fiscal years of 2005 and 2015,4026 cases were excluded because the patient died in hospital, died within 30 days after discharge, had an unknown cause of death, or had missing or erroneous data. Of the remaining 20,792 SE patients, 13,910 were randomly allocated to the derivation set and 6882 to the validation set (Fig. 1). There were 3594 cases of death due to direct and indirect causes (derivation $=2446$, validation $=1148$ ), and 1073 died due to competing risks events (derivation $=701$, validation $=372$ ). The median age of all participants was 31 years (range: 0-99), and $64 \%$ were male. Characteristics of patients in the derivation set and those in the validation set were comparable (Table 1).

\section{Developing a predictive model from the derivation set}

There were 17 candidate predictors that were included in the initial crude analysis with sub-distribution modelling (Table 1; Items marked with an asterisk [*]). After application of the forward or backward stepwise procedure, nine predictors remained relevant in the final model (Table 2).

\section{Developing a risk score from the predictive model using competing risks analysis}

Of the nine predictors included in the final model, age at first admission, a continuous predictor, was classified into age categories at five-year intervals (Table 3). After following the steps required for the point-based scoring system, scores were assigned to all predictors. The possible total score ranged from zero to 64 (Table 4). The total score was used to determine the probability of event occurrence based on the cumulative incidence function for each year point (Table 5).

\section{Validating the predictive model from both the derivation} and validation sets

The AUCs in the derivation set were $0.760,0.745,0.742$, $0.734,0.741,0.739,0.741,0.743,0.742$, and 0.738 at each

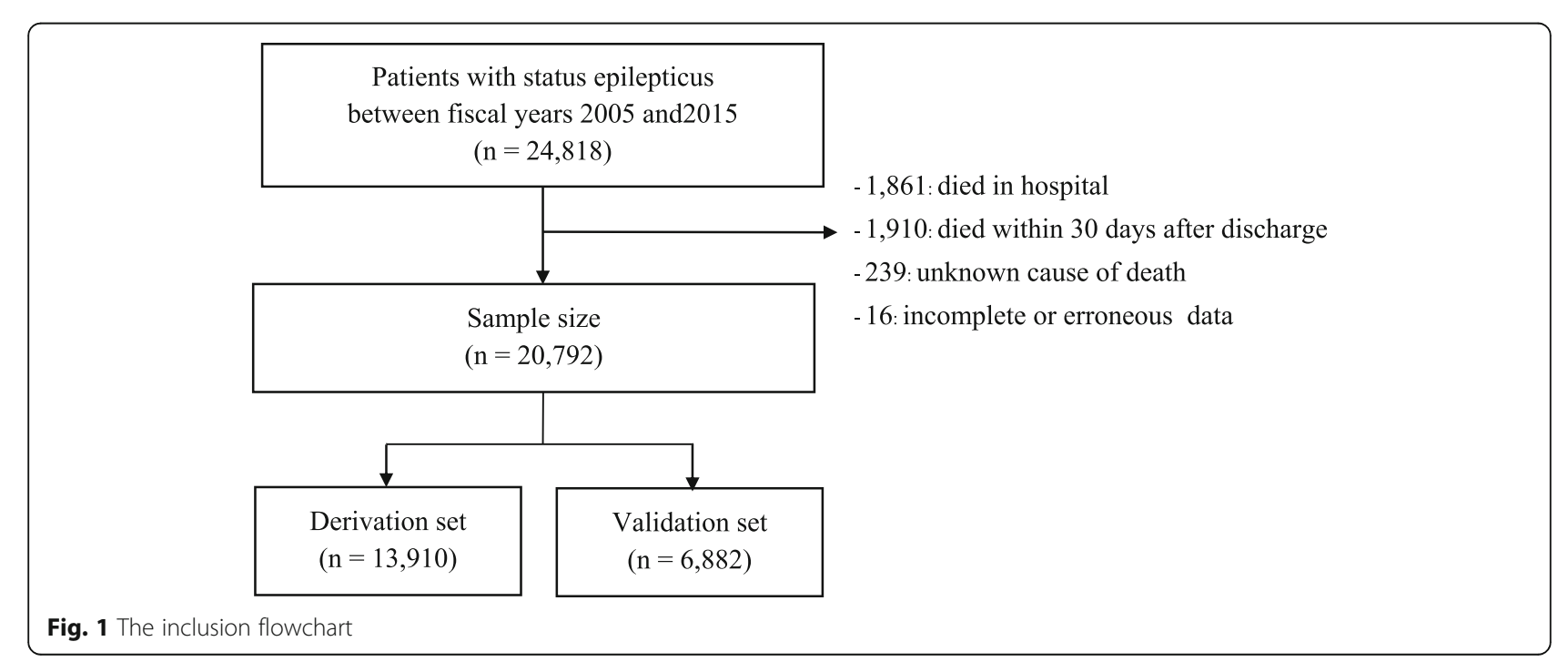


Table 1 Characteristics of admitted SE patients on the national database during fiscal year 2005-2015

\begin{tabular}{|c|c|c|c|c|}
\hline \multirow[t]{2}{*}{ Characteristics } & \multicolumn{2}{|c|}{ Derivation set } & \multicolumn{2}{|c|}{ Validation set } \\
\hline & Number & (\%) & Number & $(\%)$ \\
\hline Male* & 8836 & $(63.5 \%)$ & 4437 & $(64.5 \%)$ \\
\hline Age at first admission (years) & 31 (0: 99) & & $32(0: 94)$ & \\
\hline \multicolumn{5}{|l|}{ Status epilepticus (ICD-10 code) } \\
\hline Convulsive SE (G41.0, G41.9) & 13,417 & $(96.5 \%)$ & 6658 & $(96.7 \%)$ \\
\hline Non-convulsive SE (G41.1, G41.2) & 266 & $(1.9 \%)$ & 121 & $(1.8 \%)$ \\
\hline Other SE (G41.8) & 227 & $(1.6 \%)$ & 103 & $(1.5 \%)$ \\
\hline Brain tumor* & 93 & $(0.7 \%)$ & 44 & $(0.6 \%)$ \\
\hline Stroke* & 1682 & $(12.1 \%)$ & 826 & $(12.0 \%)$ \\
\hline Epilepsy & 1290 & $(9.3 \%)$ & 632 & $(9.2 \%)$ \\
\hline CNS infection & 256 & $(1.8 \%)$ & 132 & $(1.9 \%)$ \\
\hline Cancer* & 179 & $(1.3 \%)$ & 68 & $(1.0 \%)$ \\
\hline Diabetes* & 794 & $(5.7 \%)$ & 388 & $(5.6 \%)$ \\
\hline Hypertension* & 1381 & $(9.9 \%)$ & 675 & $(9.8 \%)$ \\
\hline Chronic kidney disease* & 250 & $(1.8 \%)$ & 125 & $(1.8 \%)$ \\
\hline Heart diseases* & 412 & $(3.0 \%)$ & 199 & $(2.9 \%)$ \\
\hline Ischemic heart disease* & 117 & $(0.8 \%)$ & 73 & $(1.1 \%)$ \\
\hline Shock* & 122 & $(0.9 \%)$ & 65 & $(0.9 \%)$ \\
\hline Septicemia* & 434 & (3.1\%) & 221 & $(3.2 \%)$ \\
\hline Hypoglycemia* & 247 & $(1.8 \%)$ & 124 & $(1.8 \%)$ \\
\hline Pneumonia* & 1672 & $(12.0 \%)$ & 827 & $(12.0 \%)$ \\
\hline Respiratory failure* & 2293 & $(16.5 \%)$ & 1157 & $(16.8 \%)$ \\
\hline Acute renal failure* & 251 & $(1.8 \%)$ & 107 & $(1.6 \%)$ \\
\hline Urinary tract infection* & 597 & $(4.3 \%)$ & 267 & (3.9\%) \\
\hline
\end{tabular}

${ }^{*}$ candidate predictors in the initial model (with $P$ value $<0.20$ in the univariate model)

**Median (Min:Max)

Table 2 Predictors associated with long-term mortality in SE ${ }^{a}$ according to the sub-distribution hazard model

\begin{tabular}{|c|c|c|c|c|c|c|c|c|}
\hline \multirow[t]{2}{*}{ Predictors } & \multicolumn{4}{|c|}{ Unadjusted } & \multicolumn{4}{|c|}{ Adjusted } \\
\hline & $\beta$ & SHR & $95 \% \mathrm{Cl}$ & $p$-value & $\beta$ & SHR & $95 \% \mathrm{Cl}$ & $p$-value \\
\hline Age at first admission (years) & 0.0256 & 1.03 & $1.02-1.03$ & $<0.001$ & 0.0211 & 1.02 & $1.02-1.02$ & $<0.001$ \\
\hline Male & 0.2432 & 1.28 & $1.17-1.39$ & $<0.001$ & 0.2458 & 1.28 & $1.17-1.40$ & $<0.001$ \\
\hline Brain tumor & 1.3641 & 3.91 & $2.92-5.24$ & $<0.001$ & 1.2451 & 3.47 & $2.52-4.79$ & $<0.001$ \\
\hline Stroke & 1.0103 & 2.75 & $2.50-3.02$ & $<0.001$ & 0.2822 & 1.33 & $1.19-1.48$ & $<0.001$ \\
\hline Cancer & 1.6646 & 5.28 & $4.23-6.60$ & $<0.001$ & 1.2065 & 3.34 & $2.58-4.33$ & $<0.001$ \\
\hline Diabetes & 1.0242 & 2.78 & $2.45-3.16$ & $<0.001$ & 0.3515 & 1.42 & $1.23-1.64$ & $<0.001$ \\
\hline Chronic kidney disease & 1.2753 & 3.58 & $2.91-4.40$ & $<0.001$ & 0.5136 & 1.67 & $1.33-2.11$ & $<0.001$ \\
\hline Pneumonia & 0.3720 & 1.45 & $1.30-1.62$ & $<0.001$ & 0.4763 & 1.61 & $1.43-1.81$ & $<0.001$ \\
\hline Urinary tract infection & 0.8843 & 2.42 & $2.09-2.80$ & $<0.001$ & 0.3946 & 1.48 & $1.27-1.74$ & $<0.001$ \\
\hline
\end{tabular}


Table 3 Point-based risk scoring system for long-term mortality in $\mathrm{SE}^{\mathrm{a}}$

\begin{tabular}{|c|c|c|c|c|c|}
\hline Predictors $^{\mathrm{a}}$ & Categories & Ref. value & $\beta_{i}^{b}$ & $\beta_{\mathrm{i}}\left(W_{\mathrm{ij}}-W_{\mathrm{iREF}}\right)$ & Points $^{c}$ \\
\hline \multirow[t]{20}{*}{ Age at first admission } & $0-4$ & $2=W_{\text {iREF }}$ & 0.0211 & 0 & 0 \\
\hline & $5-9$ & 7 & & 0.106 & 1 \\
\hline & $10-14$ & 12 & & 0.211 & 2 \\
\hline & $15-19$ & 17 & & 0.317 & 3 \\
\hline & $20-24$ & 22 & & 0.422 & 4 \\
\hline & $25-29$ & 27 & & 0.528 & 5 \\
\hline & $30-34$ & 32 & & 0.633 & 6 \\
\hline & $35-39$ & 37 & & 0.739 & 7 \\
\hline & $40-44$ & 42 & & 0.844 & 8 \\
\hline & $45-49$ & 47 & & 0.950 & 9 \\
\hline & $50-54$ & 52 & & 1.055 & 10 \\
\hline & $55-59$ & 57 & & 1.161 & 11 \\
\hline & $60-64$ & 62 & & 1.266 & 12 \\
\hline & $65-69$ & 67 & & 1.372 & 13 \\
\hline & $70-74$ & 72 & & 1.477 & 14 \\
\hline & $75-79$ & 77 & & 1.583 & 15 \\
\hline & $80-84$ & 82 & & 1.688 & 16 \\
\hline & $85-89$ & 87 & & 1.794 & 17 \\
\hline & $90-94$ & 92 & & 1.899 & 18 \\
\hline & $95-99$ & 97 & & 2.005 & 19 \\
\hline \multirow[t]{2}{*}{ Sex } & Female & $0=W_{\text {iREF }}$ & 0.2458 & 0 & 0 \\
\hline & Male & 1 & & 0.246 & 2 \\
\hline \multirow[t]{2}{*}{ Brain tumor } & No & $0=W_{\text {iREF }}$ & 1.2451 & 0 & 0 \\
\hline & Yes & 1 & & 1.245 & 12 \\
\hline \multirow[t]{2}{*}{ Stroke } & No & $0=W_{\text {iREF }} 1$ & 0.2822 & 0 & 0 \\
\hline & Yes & & & 0.282 & 3 \\
\hline \multirow[t]{2}{*}{ Cancer } & No & $0=W_{\text {iREF }}$ & 1.2065 & 0 & 0 \\
\hline & Yes & 1 & & 1.207 & 11 \\
\hline \multirow[t]{2}{*}{ Diabetes } & No & $0=W_{\text {iREF }}$ & 0.3515 & 0 & 0 \\
\hline & Yes & 1 & & 0.352 & 3 \\
\hline \multirow[t]{2}{*}{ Chronic kidney disease } & No & $0=W_{\text {iREF }}$ & 0.5136 & 0 & 0 \\
\hline & Yes & 1 & & 0.514 & 5 \\
\hline \multirow[t]{2}{*}{ Pneumonia } & No & $0=W_{\text {iREF }}$ & 0.4763 & 0 & 0 \\
\hline & Yes & 1 & & 0.476 & 5 \\
\hline \multirow[t]{2}{*}{ Urinary tract infection } & No & $0=W_{\text {iREF }}$ & 0.3946 & 0 & 0 \\
\hline & Yes & 1 & & 0.395 & 4 \\
\hline
\end{tabular}

aboth direct and indirect causes

${ }^{\mathrm{b}}$ The coefficients form the final sub-distribution hazard model

cpoints were computed by $\beta_{\mathrm{i}}\left(\mathrm{W}_{\mathrm{ij}}-\mathrm{W}_{\mathrm{iREF}}\right) /\left(5 \beta_{\mathrm{age}}\right)$ and rounded into integer value

year from years one to 10 , respectively. In the validation set, the AUCs for each year from years one to 10 were $0.761,0.743,0.740,0.734,0.722,0.725,0.733,0.737$, 0.733 , and 0.740 (Table 6).

\section{Discussion}

This study developed and internally validated a new 10year prediction score for mortality in SE patients after their first admission using a competing risks approach. This simple prediction risk score relied on demographic data, comorbidities, and complications (age, sex, brain tumor, stroke, cancer, diabetes, chronic kidney disease, pneumonia, and urinary tract infection). These finding should be considered with caution, because this study focused on the long-term mortality (outside hospital), we cannot guarantee that the indirect causes of death (accident, suicide, SE complication, and comorbidity) were due to SE. We found that age was a major predictor of mortality in SE patients, which is in accordance with results found using the STESS and EMSE $[8,9]$. 
Table 4 Risk score for long-term mortality in SE

\begin{tabular}{|c|c|}
\hline Predictors & Scores \\
\hline \multicolumn{2}{|c|}{ Age at first admission (years) } \\
\hline $0-5$ & 0 \\
\hline $6-10$ & 1 \\
\hline $11-15$ & 2 \\
\hline $16-20$ & 3 \\
\hline $21-25$ & 4 \\
\hline $26-30$ & 5 \\
\hline $31-35$ & 6 \\
\hline $36-40$ & 7 \\
\hline $41-45$ & 8 \\
\hline $46-50$ & 9 \\
\hline $51-55$ & 10 \\
\hline $56-60$ & 11 \\
\hline $61-65$ & 12 \\
\hline $66-70$ & 13 \\
\hline $71-75$ & 14 \\
\hline $76-80$ & 15 \\
\hline $81-85$ & 16 \\
\hline $86-90$ & 17 \\
\hline $91-95$ & 18 \\
\hline $96-100$ & 19 \\
\hline Male & 2 \\
\hline Brain tumor & 12 \\
\hline Stroke & 3 \\
\hline Cancer & 11 \\
\hline Diabetes & 3 \\
\hline Chronic kidney disease & 5 \\
\hline Pneumonia & 5 \\
\hline Urinary tract infection & 4 \\
\hline
\end{tabular}

${ }^{a}$ both direct and indirect causes

Similarly, brain tumor, stroke, diabetes, and chronic kidney disease have been identified as predictors using the EMSE [9]. Because this study focused on long-term mortality in SE patients, gender, cancer, pneumonia, and urinary tract infection scores differed from those found in previous studies. However, prior articles have found clear associations between these predictors and mortality in SE patients $[4,6,7,24]$, except the urinary tract infection which shown as a protective factor in previous study [7]. This is due to the difference group of patients - inpatients and after discharge within 30 days, and the outcome - all-cause mortality in SE.

The discriminatory capability of the proposed prediction model using the AUC at each year from years one to 10 were all over $70 \%$ for both the derivation and validation sets, which is slightly lower than that of the
STESS (AUC = 0.760; in-hospital death) [8]. However, a recent study examining long-term mortality utilized the STESS and found that it had a poor discriminatory ability $(\mathrm{AUC}=0.676)[11]$. Another study found that the discrimination capability of the EMSE (AUC $=0.902$; inhospital death) [9] decreased when it was applied to 30day mortality $(\mathrm{AUC}=0.832)$ [25]. Although the performance of our model was generally consistent, the $95 \% \mathrm{CI}$ of the AUC was wider in the later periods than earlier on due to the lower death rates in the later years [26].

There were three major strengths of this study as a result of our use of Thailand's Universal Coverage Scheme dataset to develop the risk score. First, it allowed us to access a large sample size consisting of patient data from multicenter and follow them over 10 years. Second, as the database contains the information of patients in all age ranges, the score we developed can be generalized to SE patients of all ages. Lastly, the Universal Coverage Scheme database is connected to that of the Ministry of the Interior, which allowed us to follow up on all patients. However, the death of patients in this study is out-of-hospital mortality. If the patients died with natural causes, the definitive cause of death would not be identified because they were not performed by autopsy, even so, the sensitivity analysis found that the AUCs of first to last time points ranged from 0.722 to 0.692 that decreased by 0.038 to 0.046 when the patients who died with comorbidities were excluded. Furthermore, most of the healthcare units lacked the capability to perform EEG (difficult to specify the type of seizure). Therefore, most of patients in this study were diagnosed with convulsive SE and our study included all type of SE in order to avoid misclassification of SE types which be lead to underestimation or overestimation. Moreover, the database did not contain information about duration of seizure and etiology, which are the important predictors associated with death in SE patients. Thus, further studies should include seizure types, duration of seizure, and etiology as predictors. In addition, we lacked of external validation due to this database containing insufficient longitudinal data. Therefore, external validation should be performed in order to evaluate the generalizability of this study.

\section{Conclusions}

In this study, we developed the first simple clinical scoring system that considers competing risks to predict long-term mortality after first admission in SE patients. The score is based on demographic data, comorbidities, and complications (age, sex, brain tumor, stroke, cancer, diabetes, chronic kidney disease, pneumonia, and urinary tract infection). The AUCs of the first to last time point ranged from 0.760 to 0.738 . This user-friendly score requires only simple information of patient that contained 
Table 5 Predicted mortality rates in $\mathrm{SE}^{\mathrm{a}}$ with individual score totals

\begin{tabular}{|c|c|c|c|c|c|c|c|c|c|c|}
\hline \multirow{2}{*}{$\begin{array}{l}\text { Score } \\
\text { points }\end{array}$} & \multicolumn{10}{|c|}{ Predicted mortality (\%) } \\
\hline & $1 \mathrm{yr}$ & 2 yrs & $3 y r s$ & 4 yrs & 5 yrs & $6 y r s$ & $7 \mathrm{yrs}$ & $8 y r s$ & $9 y$ yrs & $10 \mathrm{yrs}$ \\
\hline 0 & 2.1 & 3.2 & 4.2 & 5.3 & 6.2 & 7.0 & 7.8 & 8.5 & 9.2 & 9.8 \\
\hline 1 & 2.3 & 3.5 & 4.7 & 5.8 & 6.9 & 7.8 & 8.6 & 9.4 & 10.2 & 10.9 \\
\hline 2 & 2.5 & 3.9 & 5.2 & 6.5 & 7.6 & 8.6 & 9.5 & 10.4 & 11.2 & 12.0 \\
\hline 3 & 2.8 & 4.3 & 5.8 & 7.2 & 8.4 & 9.5 & 10.5 & 11.5 & 12.4 & 13.3 \\
\hline 4 & 3.1 & 4.8 & 6.4 & 7.9 & 9.3 & 10.5 & 11.6 & 12.6 & 13.7 & 14.6 \\
\hline 5 & 3.5 & 5.3 & 7.1 & 8.8 & 10.3 & 11.6 & 12.8 & 13.9 & 15.1 & 16.1 \\
\hline 6 & 3.8 & 5.9 & 7.8 & 9.7 & 11.4 & 12.8 & 14.1 & 15.4 & 16.6 & 17.7 \\
\hline 7 & 4.3 & 6.6 & 8.7 & 10.7 & 12.6 & 14.2 & 15.6 & 16.9 & 18.3 & 19.5 \\
\hline 8 & 4.7 & 7.3 & 9.6 & 11.8 & 13.9 & 15.6 & 17.1 & 18.6 & 20.1 & 21.4 \\
\hline 9 & 5.2 & 8.0 & 10.6 & 13.1 & 15.3 & 17.2 & 18.8 & 20.5 & 22.1 & 23.5 \\
\hline 10 & 5.8 & 8.9 & 11.7 & 14.4 & 16.8 & 18.9 & 20.7 & 22.5 & 24.2 & 25.7 \\
\hline 11 & 6.4 & 9.8 & 12.9 & 15.9 & 18.5 & 20.8 & 22.7 & 24.6 & 26.5 & 28.2 \\
\hline 12 & 7.1 & 10.9 & 14.2 & 17.5 & 20.4 & 22.8 & 24.9 & 27.0 & 29.0 & 30.8 \\
\hline 13 & 7.9 & 12.0 & 15.7 & 19.2 & 22.4 & 25.0 & 27.3 & 29.5 & 31.6 & 33.5 \\
\hline 14 & 8.7 & 13.2 & 17.3 & 21.1 & 24.5 & 27.3 & 29.8 & 32.2 & 34.5 & 36.5 \\
\hline 15 & 9.6 & 14.6 & 19.0 & 23.2 & 26.8 & 29.9 & 32.5 & 35.0 & 37.5 & 39.6 \\
\hline 16 & 10.6 & 16.1 & 20.9 & 25.4 & 29.3 & 32.6 & 35.4 & 38.1 & 40.7 & 42.9 \\
\hline 17 & 11.7 & 17.7 & 22.9 & 27.8 & 32.0 & 35.5 & 38.5 & 41.3 & 44.0 & 46.4 \\
\hline 18 & 12.9 & 19.5 & 25.1 & 30.4 & 34.9 & 38.5 & 41.7 & 44.7 & 47.5 & 49.9 \\
\hline 19 & 14.3 & 21.4 & 27.5 & 33.1 & 37.9 & 41.8 & 45.1 & 48.2 & 51.2 & 53.7 \\
\hline 20 & 15.7 & 23.5 & 30.0 & 36.0 & 41.1 & 45.2 & 48.6 & 51.8 & 54.9 & 57.5 \\
\hline 21 & 17.3 & 25.7 & 32.7 & 39.1 & 44.5 & 48.7 & 52.3 & 55.6 & 58.7 & 61.3 \\
\hline 22 & 19.1 & 28.1 & 35.7 & 42.4 & 48.0 & 52.4 & 56.1 & 59.4 & 62.6 & 65.2 \\
\hline 23 & 20.9 & 30.7 & 38.7 & 45.8 & 51.7 & 56.2 & 59.9 & 63.3 & 66.5 & 69.0 \\
\hline 24 & 23.0 & 33.5 & 42.0 & 49.4 & 55.4 & 60.0 & 63.8 & 67.2 & 70.3 & 72.8 \\
\hline 25 & 25.2 & 36.4 & 45.4 & 53.1 & 59.2 & 63.9 & 67.7 & 71.0 & 74.1 & 76.5 \\
\hline 26 & 27.6 & 39.5 & 48.9 & 56.9 & 63.1 & 67.8 & 71.5 & 74.7 & 77.7 & 80.0 \\
\hline 27 & 30.1 & 42.8 & 52.6 & 60.7 & 67.0 & 71.6 & 75.2 & 78.3 & 81.1 & 83.3 \\
\hline 28 & 32.8 & 46.3 & 56.4 & 64.6 & 70.8 & 75.3 & 78.8 & 81.7 & 84.3 & 86.3 \\
\hline 29 & 35.8 & 49.9 & 60.3 & 68.5 & 74.6 & 78.9 & 82.1 & 84.9 & 87.2 & 89.0 \\
\hline 30 & 38.8 & 53.6 & 64.1 & 72.3 & 78.2 & 82.2 & 85.2 & 87.7 & 89.8 & 91.4 \\
\hline 31 & 42.1 & 57.4 & 68.0 & 76.0 & 81.6 & 85.3 & 88.1 & 90.3 & 92.1 & 93.5 \\
\hline 32 & 45.5 & 61.2 & 71.8 & 79.5 & 84.7 & 88.1 & 90.6 & 92.5 & 94.1 & 95.2 \\
\hline 33 & 49.1 & 65.1 & 75.5 & 82.8 & 87.6 & 90.6 & 92.8 & 94.4 & 95.7 & 96.6 \\
\hline 34 & 52.7 & 69.0 & 79.1 & 85.9 & 90.2 & 92.8 & 94.6 & 95.9 & 96.9 & 97.6 \\
\hline 35 & 56.5 & 72.8 & 82.4 & 88.6 & 92.4 & 94.6 & 96.1 & 97.1 & 97.9 & 98.4 \\
\hline 36 & 60.4 & 76.4 & 85.5 & 91.1 & 94.3 & 96.1 & 97.3 & 98.1 & 98.7 & 99.0 \\
\hline 37 & 64.3 & 79.9 & 88.3 & 93.2 & 95.9 & 97.3 & 98.2 & 98.8 & 99.2 & 99.4 \\
\hline 38 & 68.1 & 83.2 & 90.8 & 94.9 & 97.1 & 98.2 & 98.8 & 99.2 & 99.5 & 99.7 \\
\hline 39 & $>71.9$ & $>86.2$ & $>92.9$ & $>96.4$ & $>98.0$ & $>98.8$ & $>99.3$ & $>99.6$ & $>99.7$ & $>99.8$ \\
\hline
\end{tabular}


Table 6 Discrimination in the derivation and validation sets

\begin{tabular}{llllll}
\hline Years & \multicolumn{2}{l}{ Derivation set } & & \multicolumn{2}{l}{ Validation set } \\
\cline { 2 - 3 } & AUC & $95 \% \mathrm{Cl}$ & & AUC & $95 \% \mathrm{Cl}$ \\
\hline 1 & 0.760 & $0.743-0.777$ & & 0.761 & $0.736-0.785$ \\
2 & 0.745 & $0.730-0.760$ & & 0.743 & $0.722-0.764$ \\
3 & 0.742 & $0.725-0.759$ & & 0.740 & $0.719-0.760$ \\
4 & 0.734 & $0.716-0.752$ & & 0.734 & $0.714-0.755$ \\
5 & 0.741 & $0.717-0.765$ & & 0.722 & $0.699-0.746$ \\
6 & 0.739 & $0.706-0.773$ & & 0.725 & $0.697-0.753$ \\
7 & 0.741 & $0.697-0.785$ & & 0.733 & $0.699-0.768$ \\
8 & 0.743 & $0.685-0.801$ & & 0.737 & $0.695-0.780$ \\
9 & 0.742 & $0.665-0.819$ & & 0.733 & $0.677-0.789$ \\
10 & 0.738 & $0.639-0.836$ & & 0.740 & $0.668-0.812$ \\
\hline
\end{tabular}

in the medical records; where clinical or laboratory data was not available. In addition, the risk score can assist the patients to realize their own risk and helps clinicians in their decision-making process about long-term plan for treatment or reduce risk of death, especially patients with high risk. Although this score can assist in the estimation of a prognosis in an individual patient after discharge as well as SE management, it still needs improvement and external validation.

\section{Supplementary information}

Supplementary information accompanies this paper at https://doi.org/10. 1186/s12883-019-1540-y.

Additional file 1: Causes of death and ICD-10 codes of predictors. Figure S1. Types of event. Table S1. Cause of death in each type of event. Table S2. ICD-10 codes of predictors

\section{Abbreviations}

AUC: Area under the receiver operating characteristic curve; $\mathrm{Cl}$ : Confidence interval; C-index: Concordance index; CNS: Central nervous system; EEG: Electroencephalogram; EMSE: Epidemiology-Based Mortality Score in Status Epilepticus; ICD-10: International Statistical Classification of Diseases and Related Health Problems 10th Revision; mRS: Modified Rankin Scale; mSTESS: Modified Status Epilepticus Severity Score; ROC: Receiver operating characteristic; SE: Status epilepticus; STESS: Status Epilepticus Severity Score

\section{Acknowledgements}

The authors wish to thank Professor Thomas Alexander Gerds for suggesting the method used to assess the performance of the model. We would also like to thank the Integrated Epilepsy Research Group (Khon Kaen University, Khon Kaen, Thailand) for providing the financial support to conduct this research.

\section{Authors' contributions}

PS, PP, and ST participated in the concept and design of study. ST requested permission to access data from the National Health Security Office. PS managed and analyzed the data. PS, PP interpreted the data. PS, PP, and ST drafted and reviewed the manuscript. All authors read and approved the final manuscript.

\section{Funding}

This study was financially supported by the Integrated Epilepsy Research Group, Khon Kaen University, Khon Kaen, Thailand.

\section{Availability of data and materials}

The datasets used or analyzed during the current study are available from the corresponding author on reasonable request.

\section{Ethics approval and consent to participate}

This study was approved by Khon Kaen University Ethics Committee for Human Research (Reference number: HE612248).

\section{Consent for publication}

Not applicable, this study utilized secondary data that cannot be used to identify any of the individual participants.

\section{Competing interests}

The authors declare that they have no competing interests.

\section{Author details}

${ }^{1}$ Department of Epidemiology and Biostatistics, Faculty of Public Health, Khon Kaen University, Khon Kaen, Thailand. ${ }^{2}$ Integrated Epilepsy Research Group, Khon Kaen University, Khon Kaen, Thailand. 'Division of Neurology, Department of Medicine, Faculty of Medicine, Khon Kaen University, Khon Kaen, Thailand.

Received: 18 December 2018 Accepted: 25 November 2019

Published online: 01 December 2019

\section{References}

1. Rui-Juan L, Wang Q, Cui T, Zhu F, Shao XQ. Status epilepticus-related etiology, incidence and mortality: a meta-analysis. Epilepsy Res. 2017;136: $12-7$

2. Shorvon SD, Andermann F, Guerrini R, editors. The causes of epilepsy : common and uncommon causes in adults and children. New York: Cambridge University Press; 2011

3. Trinka E, Höfler J, Zerbs A. Causes of status epilepticus. Epilepsia. 2012; 53(Suppl 4):127-38.

4. Tiamkao S, Pranbul S, Sawanyawisuth K, Thepsuthammarat K. A national database of incidence and treatment outcomes of status epilepticus in Thailand. Int J Neurosci. 2014:124:416-20.

5. Sutter R, Marsch S, Fuhr P, Rüegg S. Mortality and recovery from refractory status epilepticus in the intensive care unit: a 7-year observational study. Epilepsia. 2013;54:502-11.

6. Malek AM, Wilson DA, Martz GU, Wannamaker BB, Wagner JL, Smith G, et al. Mortality following status epilepticus in persons with and without epilepsy. Seizure. 2016:42:7-13.

7. Tiamkao S, Saybungkla P, Sirikarn P, Sawanyawisuth K. Group on behalf of IER. Predictors of long-term mortality in status epilepticus. Epilepsy Behav. 2018:84:114-7.

8. Rossetti AO, Logroscino G, Bromfield EB. A clinical score for prognosis of status epilepticus in adults. Neurology. 2006;66:1736-8.

9. Leitinger M, Höller Y, Kalss G, Rohracher A, Novak HF, Höfler J, et al. Epidemiology-based mortality score in status Epilepticus (EMSE). Neurocrit Care. 2015;22:273-82.

10. González-Cuevas M, Santamarina E, Toledo M, Quintana M, Sala J, Sueiras M, et al. A new clinical score for the prognosis of status epilepticus in adults. Eur J Neurol. 2016;23:1534-40.

11. Aukland $\mathrm{P}$, Lando M, Vilholm O, Christiansen EB, Beier CP. Predictive value of the status Epilepticus severity score (STESS) and its components for longterm survival. BMC Neurol. 2016:16:213.

12. Lee $Y$, Choi EJ, Hong JP, Kang JK. Mortality, causes and predictors of death in status epilepticus (P5.087). Neurology. 2015:84(Suppl 14):P5.087.

13. Austin PC, Lee DS, Fine JP. Introduction to the analysis of survival data in the presence of competing risks. Circulation. 2016;133:601-9.

14. Austin PC, Lee DS, D'Agostino RB, Fine JP. Developing points-based riskscoring systems in the presence of competing risks. Stat Med. 2016;35: 4056-72.

15. Fine JP, Gray RJ. A proportional hazards model for the subdistribution of a competing risk. J Am Stat Assoc. 1999:94:496-509.

16. Wolbers M, Koller MT, Witteman JCM, Steyerberg EW. Prognostic models with competing risks: methods and application to coronary risk prediction. Epidemiology. 2009;20:555-61.

17. Kuk D, Varadhan R. Model selection in competing risks regression. Stat Med 2013;32:3077-88. 
18. Blanche P, Kattan MW, Gerds TA. The c-index is not proper for the evaluation of t-year predicted risks. Biostatistics. 2018;20:347-57 doi:kxy006.

19. Blanche P, Dartigues JF, Jacqmin-Gadda H. Estimating and comparing timedependent areas under receiver operating characteristic curves for censored event times with competing risks. Stat Med. 2013;32:5381-97.

20. R Core Team. R: a language and environment for statistical computing. Vienna: R Foundation for Statistical Computing; 2017. https:/www.r-project.org/

21. Varadhan R, Kuk D. crrstep: Stepwise Covariate Selection for the Fine \& Gray Competing Risks Regression Model. 2015. R package version 2015-2.1. https://cran.r-project.org/package=crrstep.

22. Gray B. cmprsk: Subdistribution Analysis of Competing Risks. 2014. R package version 2.2-7. https://cran.r-project.org/package=cmprsk.

23. Gerds TA, Ozenne B: Risk Regression Models and Prediction Scores for Survival Analysis with Competing Risks. 2018. R package version 2018.10.03 https://cran.r-project.org/package=riskRegression

24. Ong C-T, Sheu S-M, Tsai C-F, Wong Y-S, Chen SC-C. Age-dependent sex difference of the incidence and mortality of status epilepticus: a twelve year nationwide population-based cohort study in Taiwan. PLoS One. 2015;10: e0122350.

25. Giovannini G, Monti G, Tondelli M, Marudi A, Valzania F, Leitinger M, et al. Mortality, morbidity and refractoriness prediction in status epilepticus: comparison of STESS and EMSE scores. Seizure. 2017:46:31-7.

26. Schünemann HJ, Oxman AD, Vist GE, Higgins JPT, Deeks JJ, Glasziou P, et al. Chapter 12: interpreting results and drawing conclusions, 12.4.1 confidence intervals. In: Higgins JPT, Green S, editors. Cochrane handbook for systematic reviews of interventions version 5.1.0: The Cochrane Collaboration; 2011. www.handbook.cochrane.org. Accessed 12 Nov 2018.

\section{Publisher's Note}

Springer Nature remains neutral with regard to jurisdictional claims in published maps and institutional affiliations.

Ready to submit your research? Choose BMC and benefit from:

- fast, convenient online submission

- thorough peer review by experienced researchers in your field

- rapid publication on acceptance

- support for research data, including large and complex data types

- gold Open Access which fosters wider collaboration and increased citations

- maximum visibility for your research: over $100 \mathrm{M}$ website views per year

At $\mathrm{BMC}$, research is always in progress.

Learn more biomedcentral.com/submissions 